\title{
PENGARUH BUDAYA ORGANISASI DAN PERSEPSI DUKUNGAN ORGANISASI TERHADAP KOMITMEN KARYAWAN
}

\author{
Ghita Sandra Amalia Alfian dan Zulkarnain \\ Fakultas Psikologi, Universitas Sumatera Utara, Medan 20155, Indonesia \\ E-mail: zulkarnain3@usu.ac.id
}

\begin{abstract}
The purpose of this study is to investigate the influence of organizational culture and perceived organizational support toward organizational commitment. The instrument was used in this study were organizational commitment scale is based on aspects of organizational commitment, organizational culture scale is based on aspects of organizational culture and perceived organizational support scale based on aspects of the perceived organizational support. This study was involved 203 banking employees. The results showed that organizational culture and perceived organizational support significantly influenced of organizational commitment. It means organizational culture and perceived organizational support contributed to increasing organizational commitment. Meanwhile, organizational culture has a greater contribution to organizational commitment than perceived organizational support. This study also showed that two aspects of organizational culture contributed to organizational commitment, there were espoused values and artifacts. An espoused value has a higher contributed to organizational commitment. Meanwhile, for perceived organizational support, fairness aspect contributed to organizational commitment.
\end{abstract}

Key words: organizational culture, perceived organizational support, organizational commitment, banking employees

\begin{abstract}
Abstrak
Penelitian ini bertujuan untuk mengetahui pengaruh budaya organisasi dan persepsi dukungan organisasi terhadap komitmen karyawan pada organisasi. Alat ukur penelitian adalah skala komitmen karyawan pada organisasi yang disusun oleh peneliti berdasarkan aspek komitmen karyawan pada organisasi, skala budaya organisasi berdasarkan aspek budaya organisasi dan skala persepsi dukungan organisasi berdasarkan aspek persepsi dukungan organisasi. Penelitian dilakukan pada 203 karyawan perbankan. Hasil penelitian menunjukkan bahwa budaya organisasi dan persepsi dukungan organisasi berpengaruh signifikan terhadap komitmen karyawan pada organisasi. Hal ini berarti budaya organisasi dan persepsi dukungan organisasi berpengaruh positif terhadap komitmen karyawan pada organisasi. Sementara itu, budaya organisasi memiliki sumbangan lebih besar terhadap komitmen karyawan pada organisasi dibandingkan variabel persepsi dukungan organisasi. Hasil penelitian juga menunjukkan bahwa terdapat dua aspek yang memberikan sumbangan terhadap komitmen karyawan pada organisasi, yaitu espoused values dan artifacts. Aspek espoused values memberikan sumbangan lebih besar terhadap komitmen karyawan pada organisasi. Sementara itu, untuk persepsi dukungan organisasi, aspek fairness memberikan sumbangan terhadap komitmen karyawan pada organisasi.
\end{abstract}

Kata-kata kunci: budaya organisasi, persepsi dukungan organisasi, komitmen organisasi, karyawan perbankan 
$\mathrm{K}$ omitmen karyawan pada organisasi merupakan salah satu hal penting yang harus diperhatikan dalam lingkungan kerja. Menurut Chow \& Holden (1997), tidak adanya komitmen karyawan pada organisasi dapat mengurangi efektivitas organisasi. Selain itu, karyawan yang memiliki komitmen pada organisasi cenderung untuk tidak berhenti dan mengundurkan diri (Wasti, 2003). Hal ini tentunya membuat perusahaan dapat mengurangi pengeluarannya untuk karyawan. Karyawan yang memiliki komitmen juga memerlukan sedikit pengawasan dibandingkan karyawan yang tidak memiliki komitmen (Ivancevich, Konopaske \& Matteson, 2007). Ivancevich, Konopaske \& Matteson (2007) juga menjelaskan bahwa seorang karyawan yang berkomitmen akan mempersepsikan dan mengintegrasikan tujuan individu dengan tujuan organisasi. Hal ini menunjukkan bahwa karyawan dapat berpikir mengenai tujuan dirinya dan tujuan organisasi sebagai satu kesatuan yang akan dicapainya.

Karyawan dalam sebuah perusahaan pada dasarnya percaya bahwa perusahaan akan memberikan penghargaan terhadap loyalitas dan komitmen mereka. Penghargaan tersebut dapat berupa jaminan untuk tetap bekerja, tunjangan yang besar dan kenaikan gaji (Darmawan, 2013). Hal ini menggambarkan bahwa karyawan akan mendapat kompensasi serta jaminan untuk dapat bekerja dalam jangka waktu yang lebih lama apabila karyawan menunjukkan kesetiaan terhadap perusahaan dan performansi kerja yang baik. Namun, dengan adanya persaingan berskala global menyebabkan perubahan terhadap kebijakan tradisional tersebut, seperti jaminan untuk tetap bekerja, senioritas dan kompensasi yang semakin diabaikan oleh perusahaan (Darmawan, 2013).. Hal ini membuat perusahaan perlu mempertimbangkan realitarealita yang terjadi dan dampaknya terhadap karyawan dan perusahaan.

$\begin{array}{lcr}\text { Secara } & \text { umum, perusahaan akan } \\ \text { menghargai dedikasi dan loyalitas } & \text { Karyawan yang secara } \\ \text { karyawannya. } & \text { Kanasionya } \\ \text { emosional berkomitmen pada organisasinya } \\ \text { akan menunjukkan performansi kerja yang }\end{array}$

tinggi, mengurangi tingkat ketidakhadiran dan kemungkinan yang rendah untuk berhenti dari pekerjaan (Meyer \& Allen, 1997; Eisenberger \& Rhoades, 2002). Sebaliknya, menurut Eisenberger \& Rhoades (2002), karyawan secara umum juga akan melihat bagaimana komitmen karyawan pada organisasi terhadap mereka. Hal ini dinilai dari penerimaan dan respect organisasi terhadap mereka, gaji dan promosi serta akses terhadap informasi organisasi.

Dalam mempertahankan komitmen karyawan pada organisasi, penghargaan intrinsik merupakan salah satu hal penting dalam komitmen karyawan (Ivancevich, Konopaske \& Matteson, 2007). Organisasi yang menyediakan kesempatan pencapaian prestasi bagi karyawan akan berdampak signifikan terhadap perilaku dan komitmennya pada organisasi. Perilaku karyawan pada hakikatnya adalah berorientasi pada tujuan (Darmawan, 2013). Dengan kata lain bahwa perilaku individu pada umumnya dirangsang oleh keinginan untuk mencapai tujuan yang dimilikinya. Keterlibatan karyawan yang tinggi dalam aktivitas di perusahaan menunjukkan komitmen yang tinggi dari karyawan tersebut. Upaya membangun komitmen digambarkan sebagai usaha untuk menjalin hubungan jangka panjang. Individu yang memiliki komitmen terhadap organisasi memiliki kemungkinan untuk tetap bertahan di perusahaan lebih tinggi dibandingkan dengan individu yang tidak memiliki komitmen. Karyawan yang memiliki komitmen akan menunjukkan perilaku seperti mengemukakan ide-ide baru dalam pekerjaannya, bersikap antusias terhadap pekerjaannya, berinisitif, aktif mengembangkan diri, orang lain maupun organisasi (Zulkarnain \& Hadiyani, 2014).

Dalam level organisasi, komitmen karyawan pada organisasi dapat dipengaruhi oleh budaya organisasi (Kozlowski, Chao, Smith \& Hedlund, 1993). Selain itu, penelitian yang dilakukan oleh O' Reilly, Chatman, dan Caldwell (1991) menunjukkan bahwa pentingnya nilai budaya organisasi dalam mempengaruhi perilaku dan sikap individu. Hal ini menunjukkan adanya hubungan antara 
person-organization fit dengan komitmen karyawan pada organisasi, dimana karyawan yang sesuai dengan budaya organisasi cenderung untuk mempunyai komitmen yang tinggi pada organisasi dan mempunyai intensitas yang tinggi untuk terus bekerja di organisasi.

Budaya organisasi merupakan suatu kekuatan sosial yang tidak tampak namun dapat menggerakkan orang-orang dalam suatu organisasi untuk melakukan aktivitas kerja (Sutrisno, 2011). Budaya organisasi yang kuat akan dapat mendukung tujuan-tujuan perusahaan, sebaliknya budaya organisasi yang lemah akan menghambat atau bertentangan dengan tujuan-tujuan perusahaan. Ketika memasuki suatu lingkungan kerja yang baru, karyawan akan masuk pada lingkungan yang memiliki nilai-nilai tertentu. Hal ini membuat mereka diharapkan untuk dapat menyesuaikan diri dengan lingkungan dan melibatkan pembelajaran mengenai nilai-nilai, pemrosesan informasi dengan cara baru dan bekerja dalam serangkaian norma, adat dan ritual yang telah terbentuk. Bagi organisasi, budaya merupakan satu hal yang sangat penting karena kemampuannya untuk mengarahkan perilaku para anggota Organisasi ke tujuan yang dikehendaki (Melinda \& Zulkarnain, 2004). Nilai-nilai yang ada organisasi akan membimbing individu untuk berperilaku baik di dalam atau di luar pekerjaannya sehingga akan beperilaku secara konsisten (Ivancevich, Konopaske \& Matteson, 2007).

Nilai-nilai yang dikembangkan dalam suatu organisasi akan menjadi sebuah budaya yang ada di organisasi tersebut. Walaupun budaya tidak dapat dilihat, namun dapat dirasakan melalui sikap, emosi dan persepsi individu yang bekerja di organisasi tersebut. Selain itu, budaya juga merupakan bagian kehidupan organisasi yang mempengaruhi perilaku, sikap dan keseluruhan efektivitas dari karyawan. Seluruh karyawan yang ada di organisasi harus dapat memahami dengan benar mengenai budaya organisasi yang ada. Susanto (1997) mengemukakan bahwa budaya suatu perusahaan dapat dimanfaatkan sebagai andalan daya saing suatu perusahaan dalam menghadapi perubahan dan tantangan. Budaya organisasi juga dapat dijadikan sebagai pengikat untuk menyamakan persepsi dan arah pandang dari karyawan terhadap suatu permasalahan sehingga akan menjadi satu kesatuan untuk mencapai tujuan perusahaan.

Pentingnya pemahaman budaya organisasi oleh karyawan disebabkan peran penting yang dimiliki karyawan dalam menentukan pencapaian dari perusahaan. Setiap perusahaan membutuhkan karyawan dalam melakukan kegiatan dan mengembangkan kualitasnya, sehingga sumber daya manusia menjadi perhatian penting bagi perusahaan dalam menghadapi persaingan dengan perusahaan lain. Dalam bekerja, karyawan akan membentuk hubungan dan interaksi dengan pihak lain, seperti atasan, rekan kerja dan sistem perusahaan. Hubungan ini akan mempengaruhi pekerjaan dan lingkungan kerja karyawan serta keterlibatannya di perusahaan. Rekan kerja dan lingkungan yang mendukung akan membuat karyawan untuk bekerja dengan baik dan optimal. Dukungan yang dirasakannya akan berbeda untuk setiap karyawan.

Setiap individu memberikan pengertian sendiri terhadap suatu stimulus, individu yang berbeda akan mempersepsikan hal yang sama dengan cara yang berbeda (Ivancevich, Konopaske \& Matteson, 2007). Hal ini menggambarkan bahwa karyawan juga akan memberikan pengertian sendiri yang berbeda meskipun terhadap stimulus yang sama seperti rekan kerja dan lingkungannya. Ivancevich, Konopaske \& Matteson (2007) juga menjelaskan bahwa persepsi merupakan salah satu aspek yang akan berpengaruh terhadap perilaku kerja karyawan. Salah satunya adalah persepsi terhadap dukungan yang diterima dari organisasi.

Persepsi dukungan organisasi
mempunyai pengaruh penting terhadap berbagai aspek dalam perilaku organisasi. Persepsi tersebut berhubungan dengan suatu kondisi dimana karyawan merasa bahwa organisasi mereka ingin memberikan kompensasi secara adil terhadap usaha atau 
kinerja, membantu karyawan memenuhi kebutuhan, memberi pekerjaan menarik dan memotivasi serta memberikan kondisi kerja yang kondusif (Eisenberger \& Huntington, 1986). Persepsi dukungan organisasi berdasarkan pada kondisi pekerjaan dan beberapa praktik sumber daya manusia yang menciptakan sikap dan perilaku positif karyawan. Perlakuan yang adil, dukungan supervisor dan reward serta kondisi pekerjaan yang mendukung menunjukkan hubungan yang kuat dengan persepsi dukungan organisasi (Eisenberger \& Rhoades, 2002). Selain itu, persepsi dukungan organisasi juga akan mempengaruhi usaha karyawan dalam mencapai tujuan organisasi (Aselage \& Eisenberger, 2003) Pendapat lain dikemukakan oleh Darmawan (2013) yang mengemukakan bahwa POS (Perceived Organizational Support) atau persepsi dukungan organisasi fokus pada perlakuan yang menguntungkan dan tingkat karyawan yang terlibat dalam hubungan timbal balik positif dengan organisasi.

Arokiasamy, Marimuthu dan Moorthy (2010) mengemukakan bahwa POS (Perceived Organizational Support) merupakan salah satu faktor dominan yang mempengaruhi komitmen karyawan pada organisasi, kecenderungan untuk turnover dan komitmen afektif. Pendapat lain dikemukakan oleh Eisenberger \& Rhoades (2002) yang menyatakan bahwa POS (Perceived Organizational Support) memiliki hubungan dengan komitmen karyawan pada organisasi dan performansi kerjanya. Setiap perusahaan tentu penting untuk memperhatikan komitmen karyawan pada organisasi sebagai pengaruh dari budaya organisasi dan persepsi dukungan organisasi.

\section{Budaya Organisasi dan Komitmen Karyawan pada Organisasi}

Menurut Robbins (2009), organisasi dengan budaya yang kuat dapat memberikan pengaruh yang bermakna bagi perilaku dan sikap karyawannya. Hal ini disebabkan oleh karyawan yang memegang nilai inti organisasi secara luas dalam suatu budaya organisasi yang kuat. Kuatnya suatu budaya memperlihatkan kesepakatan diantara anggota mengenai hal-hal yang harus dipertahankan oleh organisasi tersebut. Kesepakatan ini akan membina kohesifitas, kesetiaan dan komitmen karyawan pada organisasi yang dapat mengurangi kecenderungan karyawan untuk meninggalkan organisasi (Robbins, 2009). Robbins (2009) juga menyatakan bahwa dalam mencapai keberhasilan, organisasi perlu meningkatkan faktor kinerja organisasi dengan membentuk dan mengembangkan suatu budaya organisasi sehingga mendukung terciptanya komitmen karyawan pada organisasi dari karyawannya.

Penelitian yang dilakukan oleh Darmawan (2009) menunjukkan bahwa budaya organisasi memiliki pengaruh yang signifikan terhadap perilaku dan kinerja karyawan. Pengarahan dan pelatihan yang dilakukan dalam setiap kelompok sampel penelitian telah berhasil menanamkan nilai-nilai organisasi dalam diri setiap karyawan. Selain itu, terjadi peningkatan komitmen dan loyalitas karyawan terhadap organisasi setelah penanaman nilai organisasi yang dilakukan secara berkala dan terus menerus. Penelitian lain dilakukan oleh Silverthorne (2003) yang menemukan bahwa budaya organisasi memiliki peran penting dalam tingkatan kepuasan kerja dan komitmen karyawan pada organisasi. Budaya organisasi yang birokrasi menghasilkan level yang rendah dari komitmen karyawan pada organisasi. Sementara itu, budaya organisasi yang inovatif memiliki level komitmen karyawan pada organisasi yang sedang dan budaya organisasi yang suportif menunjukkan level komitmen karyawan pada organisasi yang tinggi dari para karyawannya.

Menurut Shoaib, Zainab, Maqsood \& Sana (2013), budaya organisasi dan komitmen karyawan pada organisasi merupakan konsep yang paling ekstensif diteliti dalam penelitian manajemen. Organisasi modern menemukan bahwa peningkatan komitmen karyawan pada organisasi dapat dilakukan dengan mengadopsi nilai-nilai dan norma-norma yang tercermin dalam budaya setelah mereka masuk ke lingkungan dimana mereka bekerja. Namun, masalah komitmen masih tetap ada dan terbukti menjadi hal yang penting untuk diperhatikan oleh perusahaan. Penelitian ini dilakukan untuk 
mengetahui pengaruh budaya organisasi pada tingkat komitmen karyawan pada organisasi dengan memperhatikan variabel demografis. Hasil penelitiannya menunjukkan bahwa salah satu jenis budaya yaitu clan culture merupakan budaya yang paling diminati oleh para karyawan. Selain itu, hasil penelitian juga menunjukkan bahwa clan culture memiliki hubungan yang paling signifikan dengan ketiga dimensi dari komitmen karyawan pada organisasi dibandingkan dengan jenis lain dari budaya. Demikian pula, ditinjau dari variabel demografis gender, ditemukan bahwa wanita lebih cenderung memiliki komitmen afektif dalam organisasi dibandingkan dengan rekanrekan pria mereka. Tidak ada perbedaan untuk continuance commitment, sedangkan pria cenderung memiliki normative commitment dibandingkan dengan wanita.

Meyer, Allen \& Smith mengemukakan bahwa karyawan dengan affective commitment yang tinggi tetap bertahan menjadi anggota organisasi karena mereka menginginkannya. Sementara itu, karyawan dengan normative atau moral commitment juga tetap bertahan menjadi anggota organisasi karena mereka merasa memang seharusnya melakukan demikian. Karyawan yang memiliki continuance commitment tinggi akan tetap menjadi anggota organisasi karena mereka merasa memerlukannya. Perbedaan motif dari bertahannya karyawan dari keanggotaan organisasi disebabkan oleh perbedaan faktor penentu dan mengakibatkan perbedaan konsekuensi.

Berdasarkan uraian di atas, maka hipotesis dalam penelitian ini adalah terdapat pengaruh positif antara budaya organisasi dengan komitmen karyawan pada organisasi.

\section{Persepsi Dukungan Organisasi dan Komitmen Karyawan pada Organisasi}

Menurut Rhoades \& Eisenberger (2002), persepsi dukungan organisasi memiliki pengaruh terhadap komitmen karyawan pada organisasi dan kepuasan kerja. Hal ini didukung oleh teori dukungan organisasi mengenai proses psikologis yang mendasari konsekuensi dari persepsi dukungan organisasi. Pertama, berdasarkan norma timbal balik, dimana persepsi dukungan organisasi wajib menghasilkan perasaan dimana karyawan memperhatikan kesejahteraan organisasi dan membantu organisasi dalam mencapai tujuannya. Kedua, kepedulian, persetujuan dan rasa hormat yang dikonotasikan oleh persepsi dukungan organisasi harus memenuhi kebutuhan sosioemosional, menyebabkan karyawan menggabungkan keanggotaan organisasi dan status peran mereka dalam identitas sosial. Ketiga, persepsi dukungan organisasi harus memperkuat keyakinan karyawan bahwa organisasi mengakui dan memberikan penghargaan terhadap peningkatan kinerja. Proses ini harus memiliki hasil yang menguntungkan baik bagi karyawan (misalnya, peningkatan kepuasan kerja dan suasana hati yang positif) dan bagi organisasi (misalnya, meningkatkan komitmen afektif dan kinerja serta rendahnya turnover).

Rhoades \& Eisenberger (2002) juga menjelaskan bahwa salah satu dampak dari persepsi dukungan organisasi adalah komitmen karyawan pada organisasi. Hal ini didukung oleh pendapat Eisenberger, Armeli, Rexwinkel, Lynch \& Rhoades (2001) yang menyatakan bahwa berdasarkan norma timbal balik, persepsi dukungan organisasi harus membuat karyawan merasa adanya kewajiban mereka untuk peduli tentang kesejahteraan organisasi. Selain itu, persepsi dukungan organisasi juga diharapkan untuk dapat membuat karyawan dan organisasi saling menjaga kepedulian (Foa \& Foa, 1980) sehingga harus meningkatkan affective commitment dari para karyawannya. Menurut Eisenberger (1986), teori dukungan organisasi menyatakan bahwa persepsi dukungan organisasi akan memperkuat affective commitment dari karyawan. Hal ini menunjukkan bahwa persepsi dukungan organisasi didefinisikan sebagai identifikasi individu dengan keterlibatannya dalam organisasi dan hubungan emosional karyawan dengan organisasi (Meyer, Irving \& Allen, 1998). Rhoades \& Eisenberger (2002) juga mengemukakan bahwa persepsi dukungan organisasi dapat menimbulkan rasa 
bertanggung jawab karyawan untuk membantu organisasi dalam mencapai tujuannya, mempunyai affective commitment terhadap organisasi dan mendorong harapan bahwa kinerja karyawan akan dihargai oleh organisasi.

Persepsi dukungan organisasi juga menjadi penghubung antara praktek sumber daya manusia dengan affective commitment dari komitmen karyawan pada organisasi, keinginan untuk meninggalkan organisasi dan menjadi penghubung dengan variabel pengalaman kerja, yaitu penghargaan organisasi, keadilan prosedural dan dukungan karyawan (Rhoades \& Eisenberger, 2002). Persepsi dukungan organisasi juga dapat meningkatkan affective commitment melalui pemenuhan kebutuhan sosioemosional seperti afiliasi dan dukungan emosional (Armeli, Eisenberger, Fasolo \& Lynch, 1998). Pemenuhan kebutuhan tersebut menghasilkan rasa memiliki organisasi yang kuat dengan melibatkan keanggotaan organisasi karyawan dan status peran mereka dalam identitas sosialnya. Menurut Shore dan Tetrick (1991) persepsi dukungan organisasi dapat mengurangi perasaan entrapment karyawan seperti continuance commitment, yang terjadi ketika karyawan dipaksa untuk bertahan di organisasi karena tingginya biaya ketika mereka meninggalkan organisasi. Selain itu, menurut Eisenberger (1986) karyawan menunjukkan pola pernyataan yang konsisten mengenai penghargaan organisasi terhadap kontribusi mereka dan apakah organisasi akan memperlakukan mereka dengan positif atau tidak dalam situasi yang berbeda. Berdasarkan uraian, maka dapat dilihat bahwa terdapat pengaruh positif antara persepsi dukungan organisasi dengan komitmen karyawan pada organisasi.

\section{METODE}

Dalam penelitian ini, terdapat 220 kuesioner yang disebarkan pada karyawan perbankan. Setelah proses pengecekan kelengkapan pengisian kusioner yang dilakukan oleh subjek penelitian, maka sebanyak 203 kuesioner yang dapat dianalisis lebih lanjut. Tingkat pemberian respon ( respon rate ) dalam penelitian ini adalah $92.27 \%$.
Analisis statistik digunakan untuk menganalisis validitas dan reliabilitas alat ukur. Dalam mengkaji validitas alat ukur, peneliti melihat alat ukur berdasarkan validitas konstrak yaitu analisis faktor. Menurut Hadi (2000), penilaian dengan validitas kontrak melihat apakah aitem yang dimaksudkan untuk mengukur faktor-faktor tertentu telah benarbenar dapat memenuhi fungsinya dalam mengukur faktor-faktor yang dimaksudkan. Uji analisis faktor dimulai dengan melihat nilai Kaiser-Meyer-Olkin (KMO) yaitu mengukur apakah sampel sudah cukup memadai. Menurut Field (2009), statitik KMO memiliki variasi nilai antara 0 hingga 1 . Nilai $\mathrm{KMO}>0.5$ merupakan nilai acuan bahwa sampel sudah cukup memadai (Kaiser, 1974; Field, 2009). Setelah itu, nilai yang dilihat adalah nilai Measure of Sampling Adequency (MSA) dengan cara membandingkan nilai koefisien korelasi yang diamati dengan nilai koefisien korelasi parsialnya. Menurut Santoso (2002) nilai MSA berkisar antara 0 hingga 1 dengan kriteria yang digunakan untuk interpretasi. Nilai MSA = 1 berarti variabel tersebut dapat diprediksi tanpa kesalahan oleh variabel yang lainnya, nilai MSA $>0.5$ berarti variabel tersebut masih dapat diprediksi dan dianalisis lebih lanjut dan nilai MSA $<0.5$ atau mendekati 0 berarti variabel tersebut tidak dapat dianalisis lebih lanjut atau dikeluarkan dari variabel lainnya.

Validitas yang kemudian dilihat adalah validitas konstrak yang dilihat berdasarkan nilai bobot faktor (loading factor) yang menunjukkan besarnya korelasi antara variabel awal dengan faktor yang terbentuk. Korelasi dengan validitas yang baik memiliki nilai loading factor lebih besar dari 0.5 (Santoso, 2000). Dalam seleksi aitem skala psikologi yang mengukur atribut afektif, parameter yang paling penting adalah daya beda atau daya diskriminasi aitem. Daya diskriminasi aitem adalah sejauhmana aitem mampu membedakan antara individu atau kelompok individu yang memiliki dan tidak memiliki atribut yang diukur (Azwar, 2009). Komputasi ini menghasilkan koefisien korelasi item total melalui formula koefisien korelasi Pearson Product Moment (Azwar, 2009). Sementara itu, 
untuk uji reliabilitas alat ukur menggunakan pendekatan konsistensi internal (Cronbach's alpha coeffecient), yaitu suatu bentuk tes yang hanya memerlukan satu kali pengenaan tes tunggal pada sekelompok individu sebagai subjek dengan tujuan untuk melihat konsistensi antar item atau antar bagian dalam skala. Teknik ini dipandang ekonomis dan praktis (Azwar, 2009).

\section{Instrumen Pengukuran Komitmen Karyawan pada Organisasi}

Pengukuran komitmen karyawan pada organisasi menggunakan skala yang disusun berdasarkan aspek komitmen karyawan pada organisasi menurut Mowday, Porter \& Steers (1982) yaitu Identification, Involvement dan Loyalty. Dalam skala ini digunakan lima pilihan jawaban yaitu terdiri dari Sangat Setuju (SS), Setuju (S), Netral (N), Tidak Setuju (TS) dan Sangat Tidak Setuju (STS). Skala ini terdiri dari 26 aitem dengan nilai Cronbach's Alpha sebesar 0.912. Hasil analisis faktor untuk aspek identification diperoleh 9 aitem dengan nilai KMO sebesar 0.785 , nilai MSA yang bergerak dari 0.634 hingga 0.821 dan nilai loading factor bergerak dari 0.594 hingga 0.839 . Aspek kedua yaitu involvement diperoleh 8 aitem dengan nilai KMO sebesar 0.754 , nilai MSA yang bergerak dari 0.639 hingga 0.818 dan nilai loading factor bergerak dari 0.568 hingga 0.839. Aspek terakhir adalah loyalty terdiri dari 10 aitem dengan nilai KMO sebesar 0.835 , nilai MSA yang bergerak dari 0.880 hingga 0.955 dan nilai loading factor bergerak dari 0.739 hingga 0.912 .

\section{Instrumen Pengukuran Budaya Organisasi}

Pengukuran budaya organisasi menggunakan skala yang disusun berdasarkan aspek budaya organisasi menurut Schein (2004) yaitu artifacts, espoused values dan basic underlying assumption Dalam skala ini digunakan lima pilihan jawaban yaitu terdiri dari Sangat Setuju (SS), Setuju (S), Netral (N), Tidak Setuju (TS) dan Sangat Tidak Setuju (STS). Skala ini terdiri dari 26 aitem dengan nilai Cronbach's Alpha sebesar 0.918. Aspek pertama adalah artifacts yang terdiri dari 9 aitem, nilai KMO sebesar 0.706 , nilai MSA yang bergerak dari 0.634 hingga 0.680 dan nilai loading factor bergerak dari 0.525 hingga 0.822. Aspek kedua adalah espoused values yang terdiri dari 9 aitem, nilai KMO sebesar 0.796, nilai MSA yang bergerak dari 0.669 hingga 0.864 dan nilai loading factor bergerak dari 0.653 hingga 0.827. Aspek terakhir adalah basic underlying assumption yang terdiri dari 8 aitem, nilai KMO sebesar 0.791 , nilai MSA yang bergerak dari 0.597 hingga 0.872 dan nilai loading factor bergerak dari 0.504 hingga 0.868

\section{Instrumen Pengukuran Persepsi Dukungan Organisasi}

Pengukuran persepsi dukungan organisasi menggunakan skala yang disusun berdasarkan aspek persepsi dukungan organisasi menurut Rhoades \& Eisenberger (2002) yaitu fairness, supervisor support dan organizational reward and job condition. Dalam skala ini digunakan lima pilihan jawaban yaitu terdiri dari Sangat Setuju (SS), Setuju (S), Netral (N), Tidak Setuju (TS) dan Sangat Tidak Setuju (STS). Skala ini terdiri dari 29 aitem dengan nilai Cronbach's Alpha sebesar 0.938. Aspek pertama adalah fairness yang terdiri dari 10 aitem, nilai KMO sebesar 0.829 , nilai MSA yang bergerak dari 0.717 hingga 0.924 dan nilai loading factor bergerak dari 0.609 hingga 0.793. Aspek kedua adalah supervisor support yang terdiri dari 9 aitem, nilai KMO sebesar 0.809 , nilai MSA yang bergerak dari 0.661 hingga 0.891 dan nilai loading factor bergerak dari 0.602 hingga 0.853. Aspek terakhir adalah organizational reward and job condition yang terdiri dari 10 aitem, nilai KMO sebesar 0.758 , nilai MSA yang bergerak dari 0.642 hingga 0.846 dan nilai loading factor bergerak dari 0.534 hingga 0.847 .

\section{HASIL}

Gambaran umum subjek penelitian menunjukkan bahwa sebagian besarnya adalah pria dengan jumlah 110 orang (54.2\%). Usia 
mayoritas adalah dibawah 30 tahun yaitu 158 orang $(77.8 \%)$. Ditunjau dari pendidikanya, subjek penelitian kebanyakan berpendidikan S1 yaitu 148 orang $(72.9 \%)$. Kemudian, bila dilihat dari lama bekerja, sebagian besar subjek penelitia bekerja dibawah 5 tahun dengan jumlah 172 orang $(84.7 \%)$. Sedangkan bidang kerja subjek penelitian lebih banyak di bidang operasional yaitu 90 orang $(44.3 \%)$.

Tabel 1

Deskripsi karakteristik subjek penelitian

\begin{tabular}{|c|c|c|c|}
\hline $\begin{array}{c}\text { Karakteristik Subjek } \\
\text { Penelitian }\end{array}$ & Profil & Jumlah & $\begin{array}{l}\text { Persentase } \\
(\%)\end{array}$ \\
\hline \multirow{2}{*}{ Jenis Kelamin } & Pria & 110 & 54.2 \\
\hline & Wanita & 93 & 45.8 \\
\hline \multirow{4}{*}{ Usia } & $\leq 30$ tahun & 158 & 77.8 \\
\hline & $>30-\leq 40$ tahun & 32 & 15.8 \\
\hline & $>40-\leq 50$ tahun & 9 & 4.4 \\
\hline & $>50$ tahun & 4 & 2.0 \\
\hline \multirow{6}{*}{ Pendidikan } & SMA & 5 & 2.5 \\
\hline & D I & 1 & 0.5 \\
\hline & D III & 46 & 22.6 \\
\hline & D IV & 1 & 0.5 \\
\hline & S 1 & 148 & 72.9 \\
\hline & S 2 & 2 & 1.0 \\
\hline \multirow{5}{*}{ Lama Bekerja } & $\leq 5$ tahun & 172 & 84.7 \\
\hline & $>5-\geq 10$ tahun & 15 & 7.4 \\
\hline & $>10-\geq 15$ tahun & 4 & 2.0 \\
\hline & $>15-\geq 20$ tahun & 2 & 1.0 \\
\hline & $>20$ tahun & 10 & 4.9 \\
\hline \multirow{3}{*}{ Bidang Kerja } & Pemasaran & 67 & 33.0 \\
\hline & Operasional & 90 & 44.3 \\
\hline & Bisnis & 46 & 22.7 \\
\hline
\end{tabular}

\section{Hasil analisis statistik}

Berdasarkan analisis korelasi Pearson menunjukkan bahwa budaya organisasi dan persepsi dukungan organisasi berkorelasi secara signifikan dengan komitmen karyawan pada organisasi. Hal ini dapat dilihat pada tabel 2.

Tabel 2

Ringkasan Korelasi Pearson

\begin{tabular}{|c|c|}
\hline $\begin{array}{c}\text { Variabel } \\
\text { Bebas }\end{array}$ & $\begin{array}{c}\text { Komitmen Karyawan } \\
\text { pada Organisasi }\end{array}$ \\
\hline $\begin{array}{c}\text { Budaya } \\
\text { Organisasi }\end{array}$ & $.578^{* *}$ \\
\hline Persepsi & \\
Dukungan & $.478^{* *}$ \\
Organisasi & \\
\hline$* * \mathrm{p}<0.01$ & \\
\hline
\end{tabular}

Selanjutnya dilakukan analisis regresi stepwise menentukan kontribusi variabel budaya organisasi dan persepsi dukungan organisasi terhadap komitmen karyawan pada organisasi. Berdasarkan hasil analisis regresi stepwise, menunjukkan bahwa variabel budaya organisasi dan persepsi dukungan organisasi merupakan prediktor positif terhadap komitmen karyawan pada organisasi. Dari nilai koefisien determinasi berganda $\left(R^{2}=0,364\right)$, kedua variabel tersebut dapat menjelaskan $36.4 \%$ varian komitmen karyawan pada organisasi. Hasil uji regresi antara budaya organisasi, persepsi dukungan organisasi dan komitmen karyawan pada organisasi dapat dilihat pada tabel 3 berikut : 
Tabel 3

Ringkasan Koefisien Estimasi Budaya Organisasi dan Persepsi Dukungan

Organisasi terhadap Komitmen Karyawan pada Organisasi

\begin{tabular}{|c|c|c|c|c|c|}
\hline \multirow{2}{*}{ Model } & \multicolumn{2}{|c|}{$\begin{array}{c}\text { Unstandardized } \\
\text { Coefficients }\end{array}$} & \multirow{2}{*}{$\begin{array}{c}\text { Standardized } \\
\text { Coefficients } \\
\text { Beta }\end{array}$} & \multirow{2}{*}{$\mathrm{t}$} & \multirow{2}{*}{ Sig. } \\
\hline & B & $\begin{array}{l}\text { Std. } \\
\text { Error }\end{array}$ & & & \\
\hline $\begin{array}{l}\text { (Constant) } \\
\text { Budaya organisasi } \\
\text { Persepsi dukungan } \\
\text { organisasi }\end{array}$ & $\begin{array}{r}13.628 \\
.681 \\
.201\end{array}$ & $\begin{array}{r}8.077 \\
.104 \\
.065\end{array}$ & $\begin{array}{l}.453 \\
.215\end{array}$ & $\begin{array}{l}1.687 \\
6.539 \\
3.102\end{array}$ & $\begin{array}{l}.093 \\
.000 \\
.002\end{array}$ \\
\hline
\end{tabular}

Sementara itu, untuk mengetahui aspekaspek budaya organisasi yang berkontribusi terhadap komitmen karyawan pada organisasi dilakukan analisis regresi stepwise. Hasil analisis menunjukkan bahwa dari tiga aspek budaya organisasi, hanya espoused values dan artifacts yang menjadi prediktor positif terhadap komitmen karyawan pada organisasi. Hasil ini dapat dilihat pada tabel 4 berikut :

Tabel 4

Ringkasan Koefisien Estimasi Aspek-Aspek Budaya Organisasi terhadap Komitmen Organisasi

\begin{tabular}{|l|r|r|r|r|r|}
\hline \multirow{2}{*}{ Model } & \multicolumn{2}{|c|}{$\begin{array}{c}\text { Unstandardized } \\
\text { Coefficients }\end{array}$} & $\begin{array}{c}\text { Standardized } \\
\text { Coefficients }\end{array}$ & \multirow{2}{*}{$\mathrm{t}$} & \multirow{2}{*}{ Sig. } \\
\cline { 2 - 4 } & \multicolumn{1}{|c|}{$\mathrm{B}$} & \multicolumn{1}{c|}{ Std. Error } & Beta & & \\
\hline (Constant) & 25.842 & 7.199 & & 3.589 & .000 \\
Espoused values & 1.563 & .216 & .461 & 7.241 & .000 \\
Artifacts & .812 & .233 & .222 & 3.491 & .001 \\
\hline
\end{tabular}

$* * \mathrm{p}<0.01, \mathrm{R}=0.596 ; \mathrm{R}^{2}=0,355$

Analisis regresi stepwise juga dilakukan untuk mengetahui aspe-aspek persepsi dukungan organisasi yang berkontribusi terhadap komitmen karyawan pada organisasi.
Hasilnya menunjukkan bahwa hanya aspek fairness yang berperan sebagai prediktor positif terhadap komitmen karyawan pada organisasi. Hasil ini dapat dilihat pada tabel 5 berikut :

Tabel 5

Ringkasan Koefisien Estimasi Aspek Persepsi Dukungan Organisasi terhadap Komitmen Karyawan pada Organisasi

\begin{tabular}{|c|c|c|c|c|c|}
\hline \multirow[t]{2}{*}{ Model } & \multicolumn{2}{|c|}{$\begin{array}{l}\text { Unstandardized } \\
\text { Coefficients }\end{array}$} & $\begin{array}{l}\text { Standardized } \\
\text { Coefficients }\end{array}$ & \multirow[t]{2}{*}{$\mathrm{t}$} & \multirow[t]{2}{*}{ Sig. } \\
\hline & $B$ & Std. Error & Beta & & \\
\hline $\begin{array}{l}\text { (Constant) } \\
\text { fairness }\end{array}$ & $\begin{array}{r}59.059 \\
1.089\end{array}$ & $\begin{array}{r}5.073 \\
.140\end{array}$ & .482 & $\begin{array}{r}11.643 \\
7.805\end{array}$ & $\begin{array}{l}.000 \\
.000\end{array}$ \\
\hline
\end{tabular}

$* * \mathrm{p}<0.01, \mathrm{R}=0.482 ; \mathrm{R}^{2}=0.233$ 


\section{PEMBAHASAN}

Hasil penelitian menunjukkan bahwa budaya organisasi dan persepsi dukungan organisasi berhubungan searah dengan komitmen karyawan pada organisasi. Hal ini berarti individu yang memiliki pemahaman budaya organisasi dan persepsi positif terhadap dukungan organisasi akan memiliki komitmen karyawan pada organisasi yang tinggi. Menurut Robbins (2009) dan Rhoades \& Eisenberger (2002), budaya organisasi dan persepsi dukungan organisasi merupakan variabel yang berpengaruh terhadap komitmen karyawan pada organisasi dari para karyawan. Ada beberapa alasan yang dapat menjelaskan hubungan antara budaya organisasi dan persepsi dukungan organisasi dengan komitmen karyawan pada organisasi. Pertama, karyawan akan loyal dengan organisasi ketika mereka merasakan bahwa nilai-nilai organisasi sesuai dengan mereka dan organisasi menghargai mereka (Tyler, 1999; Fuller, Barnett, Hester \& Relyea, 2003). Nilai-nilai ini terdapat dalam budaya organisasi dan merupakan dasar berperilaku bagi anggota organisasi. Seluruh anggota organisasi diharapkan dapat memahami budaya organisasi sehingga karyawan akan loyal dan memiliki komitmen karyawan pada organisasi yang tinggi. Sementara itu, penghargaan organisasi terhadap karyawan merupakan salah satu dukungan dari organisasi. Ketika karyawan memiliki persepsi positif terhadap dukungan organisasi, maka karyawan juga akan loyal dan memiliki komitmen karyawan pada organisasi yang tinggi.

Kedua, menurut Shoaib, Zainab, Maqsood \& Sana (2013) peningkatan komitmen karyawan pada organisasi dapat dilakukan dengan mengadopsi nilai-nilai dan norma-norma yang tercermin dalam budaya lingkungan kerjanya. Chen (2004) juga berpendapat bahwa budaya organisasi sangat penting dalam mengembangkan dan mempertahankan komitmen karyawan pada organisasi serta tingkat keterlibatan karyawan dalam sebuah organisasi. Karyawan dari sebuah organisasi akan memiliki komitmen pada organisasi mereka ketika adanya kesamaan antara nilai-nilai mereka dengan nilai-nilai organisasi (Nazir, 2005). Hal ini berarti bahwa budaya organisasi berhubungan dengan komitmen karyawan pada organisasi.

Ketiga, Eisenberger, Armeli, Rexwinkel, Lynch \& Rhoades (2001) menyatakan bahwa berdasarkan norma timbal balik, persepsi dukungan organisasi membuat karyawan merasa adanya kewajiban mereka untuk peduli tentang kesejahteraan organisasi. Rhoades \& Eisenberger (2002) juga mengemukakan bahwa persepsi dukungan organisasi dapat menimbulkan rasa bertanggung jawab karyawan untuk membantu organisasi dalam mencapai tujuannya. Hal ini berarti bahwa persepsi dukungan organisasi berhubungan dengan komitmen karyawan pada organisasi.

Keempat, hasil penelitian ini menunjukkan bahwa budaya organisasi dan persepsi dukungan organisasi merupakan variabel yang mempengaruhi komitmen karyawan pada organisasi. Individu yang memiliki skor tinggi pada budaya organisasi dan persepsi dukungan organisasi juga akan memiliki skor tinggi pada komitmen karyawan pada organisasi. Sebaliknya, individu yang memiliki skor rendah pada budaya organisasi dan persepsi dukungan organisasi juga akan memiliki skor rendah pada komitmen karyawan pada organisasi. Hal ini berarti, individu yang memahami budaya organisasi dan memiliki persepsi positif terhadap dukungan organisasi akan cenderung memiliki komitmen karyawan pada organisasi yang tinggi. Sementara itu, individu yang tidak memahami budaya organisasi dan memiliki persepsi negatif terhadap dukungan organisasi akan cenderung memiliki komitmen karyawan pada organisasi yang rendah.

Penelitian ini juga melihat kontribusi aspek-aspek dari variabel budaya organisasi dan persepsi dukungan organisasi pada komitmen karyawan pada organisasi. Dalam variabel budaya organisasi, aspek yang memberi kontribusi terhadap komitmen karyawan pada organisasi adalah aspek espoused values dan artifacts. Aspek espoused values memberikan sumbangan lebih besar 
daripada aspek artifacts. Hal ini menunjukkan bahwa karyawan yang memiliki keyakinan mengenai nilai-nilai organisasi dan menjadikannya sebagai dasar dalam mengevaluasi hal yang benar dan salah lebih memiliki komitmen karyawan pada organisasi sehingga karyawan tersebut dapat menerima tujuan dan nilai organisasi, memberikan usaha yang lebih terhadap organisasi serta menjaga keanggotaan dalam organisasi. Hasil penelitian ini didukung oleh pendapat Sabir, Razzaq \& Yameen (2010) yang menyatakan bahwa espoused values menunjukkan nilai-nilai dari suatu organisasi dan secara signifikan berkorelasi dengan komitmen karyawan pada organisasi. Espoused values merupakan nilainilai organisasi di mana beberapanya wajib untuk diikuti dan dilaksanakan oleh pemimpin atau manajer suatu organisasi (Sabir, Razzaq \& Yameen, 2010). Pemimpin organisasi menetapkan target bagi karyawan, menekankan pada prestasi dan memungkinkan waktu cuti yang meningkatkan komitmen karyawan pada organisasi (Coper, 2003; Sabir, Razzaq \& Yameen, 2010).

Pelaksanaan strategi mengenai budaya organisasi mendukung komitmen karyawan (Sabir, Razzaq \& Yameen, 2010). Strategi kepemimpinan dan nilai-nilai yang dimiliki organisasi juga dapat mengurangi ketidakpastian karyawan dan mendorong komitmen karyawan pada organisasi (Whetten \& Cameron, 2004; Sabir, Razzaq \& Yameen, 2010). Selain itu, Sathe (1983) juga berpendapat bahwa espoused values yang merupakan aspek dari budaya organisasi membantu dalam menghasilkan identifikasi dan keterikatan pada organisasi sebagai aspek dari komitmen karyawan pada organisasi.

Sementara itu, aspek basic underlying assumption tidak memberikan kontribusi terhadap komitmen karyawan pada organisasi. Hal ini menunjukkan bahwa keyakinan yang dianggap sudah ada dan menjadi kebiasaan oleh anggota suatu organisasi tidak mempengaruhi tingkat komitmen karyawan pada organisasi. Hal ini didukung oleh pendapat Schein (1990) yang menyatakan bahwa basic underlying assumption dapat mempengaruhi tingkat komitmen karyawan pada organisasi ketika diikuti dengan espoused values karyawan. Fink (1992) juga menjelaskan bahwa basic underlying assumption yang diikuti dengan pemahaman mengenai nilai-nilai organisasi dapat membantu dalam peningkatan komitmen karyawan pada organisasi.

Variabel kedua adalah persepsi dukungan organisasi yang juga dilihat kontribusinya terhadap komitmen karyawan pada organisasi. Dalam variabel ini, aspek yang memberi kontribusi terhadap komitmen karyawan pada organisasi adalah aspek fairness. Hal ini menunjukkan bahwa keyakinan karyawan akan diperlakukan secara adil akan membuat mereka lebih memiliki komitmen karyawan pada organisasi sehingga dapat menerima tujuan dan nilai organisasi, memberikan usaha yang lebih terhadap organisasi serta menjaga keanggotaan dalam organisasi. Selanjutnya, terdapat tiga keyakinan yang terbukti memiliki hubungan kuat dengan komitmen karyawan pada organisasi, yaitu kepercayaan bahwa organisasi mendukung, memperlakukan karyawan secara adil dan memperhatikan harga diri serta kompetensi karyawan (Chungtai \& Zafar, 2006; Annisa \& Zulkarnain, 2013).

Menurut Annisa \& Zulkarnain (2013) karyawan akan memberikan apa yang ada dalam dirinya kepada organisasi dan sebaliknya mereka juga akan menuntut supaya organisasi memberikan apa yang menjadi keinginannya. Sumbangan tersebut seperti usaha, keterampilan, loyalitas, kreativitas serta lainnya yang membuat individu tersebut menjadi sumber daya bagi organisasi. Hal tersebut membuat organisasi memberikan imbalan kepada karyawan yang dapat berupa gaji, fasilitas, status, keamanan kerja dan sebagainya (Annisa \& Zulkarnain, 2013). Jika adanya keseimbangan antara harapan dan kenyataan, akan membuat karyawan terpuaskan dan menunjukkan hubungan yang positif dengan organisasi yang pada akhirnya mengarah pada terbentuknya komitmen (Aktami, 2008; Annisa \& Zulkarnain, 2013). 
Selain itu, menurut Lee, Lee \& Yang (2009) keadilan yang diberikan oleh organisasi memiliki dampak positif terhadap komitmen karyawan pada organisasi. Penelitian yang dilakukan oleh Lee, Lee \& Yang (2009) menunjukkan bahwa karyawan Information System cenderung memiliki lebih banyak kemauan untuk mengabdikan diri mereka pada organisasi, kemudian memberikan kontribusi bagi keberhasilan pekerjaan ketika mereka diperlakukan dengan adil.

Sementara itu, aspek supervisor support dan organizational reward and job condition tidak memberikan kontribusi terhadap komitmen karyawan pada organisasi. Hal ini berarti dukungan yang diterima dari supervisor dan penghargaan yang diberikan organisasi tidak memiliki kontribusi terhadap komitmen karyawan pada organisasi. Hal ini didukung oleh pendapat Pazy \& Ganzach (2006) yang menyatakan bahwa peningkatan peran supervisor support dan organizational reward tidak relevan dengan komitmen karyawan pada organisasi. Supervisor support dan organizational reward tidak bertujuan untuk menentukan komitmen karyawan pada organisasi. Menurut Wayne, Shore, Bommer \& Tetrick (2002), supervisor support lebih penting untuk melihat performansi karyawan dibandingkan hubungan dengan organisasi, termasuk komitmen karyawan pada organisasi.

Hasil penelitian berikutnya adalah melihat gambaran skor yang diperoleh dari masing-masing variabel. Pertama, dalam variabel komitmen karyawan pada organisasi, dimana sebagian besar subjek penelitian memiliki komitmen karyawan pada organisasi yang tinggi. Hal ini menunjukkan bahwa karyawan menerima dan menghayati tujuan dari organisasi, bersedia untuk terlibat dalam suatu pekerjaan serta merasa sebagai anggota organisasi dan mempertahankan keanggotaan tersebut.

Kedua, dalam variabel budaya organisasi sebagian besar subjek penelitian memiliki budaya organisasi yang kuat. Hal ini menunjukkan bahwa sebagian besar karyawan mengetahui tanda dan simbol dari organisasi, memiliki keyakinan mengenai nilai-nilai organisasi dan hal-hal yang dianggap telah menjadi kebiasaan organisasi berdasarkan pendapat atau asumsi anggotanya.

Variabel terakhir adalah persepsi dukungan organisasi. Sebagian besar subjek penelitian memiliki persepsi positif terhadap dukungan organisasi serta tidak ada subjek penelitian yang memiliki persepsi negatif terhadap dukungan organisasi. Hal ini menunjukkan sebagian besar karyawan meyakini bahwa mereka diperlakukan secara adil oleh organisasi, mendapat dukungan dari supervisor yang memperhatikan kesejahteraan mereka dan organisasi yang memberikan kesempatan pada mereka untuk mendapatkan penghargaan dan memperhatikan kondisi kerja karyawan.

\section{KESIMPULAN}

Hasil penelitian menunjukkan bahwa budaya organisasi yang kuat dan persepsi positif terhadap dukungan organisasi berhubungan searah dengan komitmen karyawan pada organisasi yang juga tinggi. Hal ini ditunjukkan dengan skor tinggi pada budaya organisasi dan persepsi dukungan organisasi seiring dengan skor tinggi pada komitmen karyawan pada organisasi. Karyawan yang memiliki komitmen pada organisasi akan memiliki keyakinan dan penerimaan terhadap tujuan dan nilai organisasi, adanya kemauan untuk memberikan usaha yang lebih terhadap organisasi dan dorongan untuk menjaga keanggotaan dalam organisasi. Karyawan akan cenderung memberikan hasil pekerjaan yang terbaik dan tetap bertahan dalam organisasi ketika karyawan memiliki pemahaman yang kuat mengenai nilai-nilai organisasi. Nilai-nilai organisasi ini tercantum dalam budaya organisasi yang juga terdiri dari keyakinan dan asumsi yang akan dijadikan sebagai pedoman dalam berperilaku di organisasi dan usaha mencapai tujuan organisasi. Sementara itu, karyawan yang memiliki persepsi positif terhadap dukungan organisasi cenderung percaya dan yakin bahwa organisasi akan 
menghargai kontribusi dan mempedulikan kesejahteraan mereka.

\section{DAFTAR RUJUKAN}

Aktami, B. (2008). Kontribusi kepuasan kerja dan iklim organisasi terhadap komitmen karyawan. Paper. Universitas Gunadarma.

Allen, M. W., Armstrong, D.J., Reid, M. F. \& Riemenschneider, C.K. (2008). Factors impacting the perceived organizational support of it employees. Information \& Management, 45(8), 556-563.

Allen, D., Shore, L., \& Griffeth, R. (1999). A model of perceived organizational support. (Unpublished Manuscript). University of Memphis and Georgia State University.

Annisa \& Zulkarnain. (2013). Komitmen terhadap organisasi ditinjau dari kesejahteraan psikologis pekerja. INSAN,Media Psikologi, 15 (1), 54-62.

Armeli, S., Eisenberger, R., Fasolo, P. \& Lynch, P. (1998). Perceived organizational support and police performance : The moderating influence of socioemotinal needs. Journal of Applied Psychology, 83, 288-297.

Arnold, P., (2005). Effective leadership and partnerships: Making democracy work, civic traditions in modern Italy. Paper. Princeton University Press.

Arokiasamy, L., Marimuthu, M,. \& Moorthy, M. K. (2010). A study on the perceived organizational support in the financial industry in Malaysia : A literature review. Interdisciplinary Journal of Contemporary Research in Business, 2 (7). 438-452

Aselage, J., \& Eisenberger, R. (2003). Perceived organizational support and psychological contracts: A theoretical integration. Journal of Organizational Behavior, 24, 491-509.

Azwar, S. (2009). Penyusunan skala psikologi. Yogyakarta : Pustaka Pelajar.
Azwar, S. (2009). Reliabilitas dan validitas. Yogyakarta : Pustaka Pelajar.

Baron, R. A., \& Greenberg, J. (1990). Behavior in organizations: Understanding and managing the human side of work (3rd ed.). Boston : Allyn \& Bacon.

Beck, K, \& Wilson, C. (2000). Development of affective organizational commitment : A crosssequental examination of change with tenure. Journal of Vocational Behaviour, 56, 114-136.

Best, P.W. (1994). Locus of control, personal commitment and commitment to the organisation. (Unpublished thesis). University of South Africa, Pretoria

Chen, L. Y. (2004). Examining the effect of organization culture \& leadership behaviors on organizational commitment, job satisfaction \& job performance at small \& middle-sized firms of Taiwan. The Journal of American Academy of Business, 5, 432438.

Chow, S., \& Holden, R. (1997). Toward an understanding of loyalty: The moderating role of trust. Journal of Managerial Issues, 9 (3), 275-298.

Chungtai, A.A., \& Zafar, S. (2006). Antecendent and consequences of organizational commitment smong Pakistani university teachers. Applied Human Resource Management Research, 11(1), 3964.

Coper, D.J. (2003). Leadership for follower commitment. Oxford, UK : Butterworth Heinemann.

Cropanzano, R., \& Greenberg, J. (1997). Progress in organizational justice: Tunneling through the maze. International Review of Industrial and Organizational Psychology, 12, 317-372.

Curry, J. P., Wakefield, D. S., Price, J. L., \& Mueller, C. W. (1996). On the casual ordering of job satisfaction, job involvement 
and organisational commitment. Academy of Management Journal, 27, 210 -230.

Darmawan, D. (2009). Budaya organisasi dan pengaruhnya terhadap perilaku dan kinerja karyawan bank. Jurnal Media Mahardhika. $48-60$

Darmawan, D. (2013). Prinsip - prinsip perilaku organisasi. Surabaya : Pena Semesta.

Dekker, I., \& Barling, J. (1995). Workforce size and work related role stress. Work and Stress, 9, 45-54.

Eisenberger, R. \& Huntington, R. (1986). Perceived organizational support. Journal of Applied Psychology, 71(3), 500-507.

Eisenberger, R., Rhoades, L., \& Cameron, J. (1999). Does pay for performance increase or decreased perceived self determination and intrinsic motivation?. Journal of Personality and Sosial Psychology, 77, 1026-1040.

Eisenberger, R., Armeli, S., Rexwinkel, B., Lynch, P.D., \& Rhoades, L. (2001). Reciprocation of perceived organizational support. Journal of Applied Psychology, 86, 42-51.

Eisenberger, R., \& Rhoades, L. (2002). Perceived organizational support: A review of the literature. Journal of Applied Psychology, 87 (4), 698-714

Field, A. (2009). Discovering statistics using SPSS third edition. London: Sage.

Foa, E. B., \& Foa, U. G. (1980). Resource theory: Interpersonal behavior as exchange. Social exchange: Advances in theory and research, 77-94.

Fuller, J.B., Barnett, Hester, K. \& Relya, C. (2003). A social identity perspective on the relationship between perceived organizational support and organizational commitment. The Journal of Social Psychology, 143(6), 789-791.

Gaertner, S. (1999), Structural determinants of job satisfaction and organizational commitment in turnover models. Human
Resource Management Review, 9 (4), 479493.

Greenberg, J. (1990). Organizational justice: Yesterday, today and tomorrow. Journal of Management, 16, 399-432.

Hadi, S. (2000). Metodology research jilid I, II ,III. Yogyakarta : Andi Offset.

Hollenbeck, J.R, \& Klein, H.J. (1987). Goal commitment and the goal setting process: Problems, prospects and proposals for future research. Journal of Applied Psychology, 72(2), 212-220.

Hutcheson, G \& Sofroniou, N. (1999). The multivariate social scientist. London : Sage

Ivancevich, Konopaske \& Matteson. (2007). Perilaku dan manajemen organisasi jilid I \& II. Jakarta : Erlangga

Kaiser, H.F. (1974). An index of factorial simplicity. Psychometrika, 35, 401-415.

Kerlinger, F.N., \& Lee, H.B. (2000). Foundations of behavioral research (4th edition). Fort Worth, TX : Harcourt College Publishers.

Kottke, J.L., \& Sharafinski, C.E. (1988). Measuring perceived supervisory and organizational support. Educational and Psychological Measurement, 48, 1075-1079.

Kozlowski, S., Chao, G., Smith, E., \& Hedlund, J. (1993). Organizational downsizing: Strategies, interventions and research implications. International Review of Industrial and Organizational Psychology, 8, 263-332.

Krishnan, J., \& Mary, S. (2012). Perceived organisational support : An overview on its antecedents and consequences. International Journal of Multidisciplinary Research. 2 (4), 1-13.

Lazarus, R.S., \& Folkman, S. (1984). Stress, appraisal and coping. New York : Springer

Lee, C., Lee, J.H., \& Yang, J.I. (2009). The impact of employees: Perceived fairness on organizational commitment in post-merger information system integration. Presented at 
The $9^{\text {th }}$ International Conference on Electronic Business, Macau.

Mathieu, J.E., \& Zajac, D. (1990). A review and meta analysis of the antecedents, correlates and consequences of organizational commitment. Psychological Bulletin, 108, 171-194.

Mehta, K. (2013). Impact of perceived organizational support on organization commitment among salesdepartment employees in Pharma Industry. (Unpublished final project report). Kadi Sarva Vishwa Vidhyalaya University.

Melinda, T. \& Zulkarnain. (2004). Budaya perusahaan dan persepsi pengembangan karir pada karyawan yang bekerja di PT. Telekomunikasi Indonesia. Jurnal Psikologi, $1,55-62$

Meyer, J.P \& Allen, N.J. (1997). Commitment in the workplace: Theory, research and application. Thousand Oaks, CA: Sage

Meyer, J.P, Allen, N.J. \& Gellantly, I. R. (1990). Affective and continuance commitment to the organization: Evaluation of measures and analysis of concurrent and time-lagged relations. Journal of Applied Psychology, 75, 710-720.

Meyer, J.P, Allen, N.J. \& Smith, C. (1993). Commitment to organizations and occupations: Extension and test of a threecomponent conceptualization. Journal of Applied Psychology, 78, 538-551.

Meyer, J.P., Allen, N.J., \& Irving, G. P. (1998). Test of the moderating effect of work values on the the relations between early work experiences and organizational commitment. Journal of Organizational Behavior, 19, 2952

Miller, D., \& Lee, J. (2001). The people make the process: Commitment to employees, decision making, and performance. Journal of Management, 27 (2), 163-189.

Miller, K. (2003). Values, attitudes and job satisfaction In Robbins, S.P., Odendaal A. \& Roodt, G. (eds), Organisational Behaviour:
Global and Southern African Perspectives. Cape Town: Pearson Education South Africa.

Morrow, P.C. (1993). The theory and measurement of work commitment. Greenwich : JAI Pres.

Mowday, R.T, Porter, L.W \& Steers, R.M. (1982). Employee-organization linkages : The psychology of commitment, absenteeism and turnover. New York: Academic Press.

Nazir, N.A. (2005). Person-culture fit and employee commitment in banks. Vikalpa, 30 (3), 39-51.

O' Reilly, C.A. (1989). Corporation's culture and commitment: Motivation and social control in organizations. California Managemen Review, 31(4): 9-25

O’ Reilly, C.A., Chatman, J., \& Caldwell, D.F. (1991). People and organizational culture : A profile comparison approach to assessing person-organization fit. The Academy of Management Journal, 34 (3), 487-516.

O’ Reilly, C.A., \& Chatman, J. (1996). Culture as social control: Corporations, cults and commitment. Research in Organizational Behavior, 18. 157-200.

Randall, D. M. (1990). The consequences of organizational commitment: Methodological investigation. Journal of Organizational Behavior, 11, 361-378.

Reichers, A. E. (1985). A review and reconceptualization of organizational commitment. Academy of Management Review, 10, 465-476.

Rhoades, L., \& Eisenberger, R. (2002). Perceived organizational support: A review of the literature. Journal of Applied Psychology, 87, 698-714.

Robbins, S. (2009). Management, $10^{\text {th }}$ edition. New Jersey : Pearson Prentice Hall.

Robbins, S., \& Judge, T. (2007). Perilaku organisasi. Jakarta : Salemba Empat. 
Sabir, M. S., Razzaq, A., \& Yameen, M. (2010). Impact of organizational culture on the employees commitment: Relationship between levels of organizational culture with commitment. KASBIT Business Journal. $3(1), 88-95$.

Sathe, V. (1983). Implication of corporate culture: A manager's guide to action. Organizational Dynamics. 12(4), 4-23.

Shane, Mc \& Glinow, V. (2009). Organizational behavior [essentials] 2nd edition. Sydney: McGraw Hill.

Santoso, S. (2002). Statistik multivariat. Jakarta : PT. Elex Media Komputindo.

Sarwono, J. (2006). Metode penelitian kuantitatif \& kualitatif. Yogyakarta : Graha Ilmu.

Schein, E. (1990). Organizational culture. American Psychologist, 45 (2), 109-19.

Schein, E. (2004). Organizational culture and leadership $\left(3^{\text {rd }}\right.$ ed.). San Fransisco: JossyBass.

Shoaib, A., Zainab, N., Maqsood, H., \& Sana, R. (2013). Impact of organizational culture on organizational commitment: A comparative study of public and private organizations. Research Journal of Recent Sciences. 2(5), 15-20.

Shore, L.M., \& Shore, T. H. (1995). Perceived organizational support and organizational justice, in R. S. Cropanzano and K. M. Kacmar (eds.), Organizational Politics, Justice, and Support : Managing the Social Climate of the Workplace Westport (149164). Westport, CT: Quorum.

Shore, L.M., \& Tetrick, L.E. (1991). A construct validity study of the survey of perceived organizational support. Journal of Applied Psychology, 76, 637-643.

Silverthorne, C. (2003). Individual / organizational fit, organizational culture, commitment and job satisfaction in Taiwan. Presented at the XI th European Congress on Work and Organizational Psychology, Lisbon, Portugal.
Storey, J. (1995). Human resource management: Still marching on, or marching out. Human Resource Management: A Critical Text, 3-32.

Susanto. (1997). Budaya perusahaan. Jakarta: Elex Media Komputindo.

Sutrisno, E. (2011). Budaya organisasi. Jakarta: Kencana.

Tyler, T. R. (1999). Why people cooperate with organizations: An identity-based perspective. Research in Organizational Behavor. 201-247.

Wasti, S. A. (2003). Organizational commitment, turnover intentions and the influence of cultural values. Journal of Occupational and Organizational Psychology, 76(3), 303-321.

Wayne, S.J, Shore, L.M \& Liden, R.C. (1997). Perceived organizational support and leader member exchange: A social exchange perspective. Academy of Management Journal, 40, 82-111.

Wayne, S.J., Shore, L.M., Bommer, W.H. \& Tetrick, L.E. (2002). The role of fair treatment and rewards in perceptions of organizational support and leader-member exchange. Journal of Applied Psychology, 87, 590-598.

Whetten, D.A., \& Cameron, K.S. (2004). Developing management skills (6th edition). NJ : Pearson Educations Inc.

Williams, L. J., \& Anderson, S. E. (1991). Job satisfaction and organizational commitment as predictors of organizational citizenship and in-role behaviors. Journal of Management, 17(3), 601-617

Zaffane. (1994). Patterns of organizational commitment and perceived management style: A comparison of public and private sector employees. Human Relations, 47(8), 977-1011.

Zulkarnain \& Hadiyani, S. (2014). Peranan komitmen organisasi dan employee engagement terhadap kesiapan karyawan untuk berubah. Jurnal Psikologi, 41(1), 1935 . 
